\title{
Exploration of Vocal Music Education with National Characteristics
}

\author{
Li Fu
}

Missfuli Aba Teachers University, Wenchuan, Sichuan, 623002

Keywords: vocal music education; national characteristics; exploration

\begin{abstract}
The country's professional national vocal music education is based on the Western music education system with China's education system as its background. In the course of its development, it has always adhered to the principle of having both national characteristics and scientific vocal methods. After a long period of development, it has achieved good results. However, the singer's singer style was too single, which led to the thinking and concern from people. From the perspective of multi-dimensional analysis, problems and causes of the development of professional national vocal music education in China, and specific solutions are put forward in this paper.
\end{abstract}

\section{Introduction}

With the continuous development of economic globalization, music and cultural exchanges between countries have become closer, gradually forming a multicultural culture. The emergence of a multicultural pattern has provided opportunities for the development of national vocal music in various countries of the world, but at the same time it has also brought challenges to our traditional national vocal music. Therefore, how to improve the level of national vocal music education in a multicultural environment is a problem that needs special attention in the current vocal music teaching in China. This article briefly analyzes the significance of the development of national vocal music under the multi-cultural pattern, outlines the problems existing in the national vocal music education in China, and discusses specifically the national vocal music education strategies under the multi-cultural pattern.

The Chinese national vocal music art is an extremely broad concept of art. Since China is a nation that contains many nationalities, various nationalities have formed different forms of artistic civilization in their development. Take vocal music as an example. Due to the different living environment, living habits, production methods, and differences in language standards of ethnic minorities in China, their vocal music also has unique national characteristics. Minorities vocal music is an important treasure of Chinese art and culture. Actively attaches great importance to the continuous development of the vocal music connotation of ethnic minorities in China. Taking the genre of Chinese minority folk songs as an example, the genres of the ethnic minorities are diverse and varied, including folk songs, labor songs, custom songs, sacrificial songs, narrative songs, and lullabies. The Mongolian pastoral songs, the Miao's flying songs, and the Dai songs are all part of the folk song category. Ethnic minorities have various religious beliefs, such as Taoism, Buddhism, Shamanism, Islam, etc. Therefore, there are many types of religious ritual songs. Therefore, it is necessary to study the positioning and development of our ethnic minority vocal arts.

\section{The Significance of Developing National Vocal Music Education and Problems in Vocal Music Education}

The multi-cultural structure provides a better opportunity for the integration of the world's national vocal music, and can promote the mutual exchange of world music culture. National vocal music education has always been the mainstream of music culture. Developing national vocal music education under the pattern of multiculturalism can not only transfer the singing of national national vocal music to the world, but also can absorb foreign national vocal music and realize national vocal music and foreign national vocal music. The fusion. Of course, to achieve this, we need to be able to learn from foreign advanced educational concepts and educational ideas in the process of 
national vocal music education, and carry out reforms in national vocal music education. We will respect and appreciate the music culture of various countries. We will carry out national vocal music education in a multicultural environment, promote the development of national vocal music education in China, accelerate the pace of national vocal music education in the world, and expand the influence of national vocal music education in the world.

Judging from the current situation of national vocal music education in music schools in China, although most music schools in China have set up national vocal music education courses, overall, the setting of these courses still needs improvement. The traditional music academies have a wide range of courses for national vocal music education. Such a course arrangement can improve students' overall quality, but over-comprehensiveness will lead to the restriction of students' individuality development. From the perspective of national vocal music education, although China's music academies arrange some basic courses in national vocal music education, most of these courses are based on basic music courses and do not highlight the national character of national vocal music. We can find in the course arrangement of the music academies that for the content of traditional musical instruments and the traditional national vocal music content, there are fewer curriculum arrangements in various institutions, which leads to students' lack of understanding of traditional national vocal music. [1] National vocal music education in many colleges and universities is to enable students to master basic traditional folk songs or to allow students to simply understand the basic vocal music knowledge of the nation, but for systematic knowledge of national vocal music such as social knowledge, historical knowledge, and humanistic knowledge, etc. Students know very little. National vocal music education is our country's traditional vocal music education. Students are required to enhance their mastery of national vocal music by strengthening their understanding of the national vocal music system. They only rely on basic vocal vocals to perform national vocal music education, and only enable students to master national vocal music education. "Forms" cannot grasp the "innerness" of national vocal music education.

After a long period of development, our nation's national vocal music education has always been gradually developed and formed by relying on the integration of various nationalities in China, and it has its own national characteristics. However, since the "May 4th Movement" began, our country's national vocal music education has begun to incorporate Western vocal music features. National vocal music education began to focus on the West Bel Canto in the process of inheritance. This kind of integrated national vocal music education has been extended to the present, resulting in the current national vocal music education in our country has too much emphasis on vocal singing, internal deficiency and serious form. It is very unfavorable to promote our national vocal music education. At present, the development of national vocal music education in our country is lagging behind. Especially in the training of excellent national vocal talents, most students have low learning efficiency. Only the knowledge of national vocal music theory is known in the study, and the practical ability is poor, which severely limits the national vocal music in China. The long-term development of education. [2] With the continuous development of the times, many people began to misunderstand the national vocal music education in our country. They began to believe that the so-called national vocal music education is the beautiful acoustic music, and only the national vocal music that blends the western vocal music is true. National vocal music education, the phenomenon of blind worship of Western Bel Canto, does not correctly recognize the shortcomings and advantages of Western Bel Canto. Of course, there are many who will allow students to learn the basic bel canto singing in teaching, and then perform national vocal music education, that is, students can use bel canto singing in the national vocal music works. Although this teaching method seems to have teaching significance, it can mobilize students' enthusiasm for learning and improve their singing ability. However, from the perspective of nationality, this teaching model seriously ignores the nationality of national vocal music education. Formalized national vocal music can be performed without being able to grasp the national characteristics of culture, and can not cultivate their own personality style. 


\section{Development Strategies of Professional National Vocal Music Education}

To promote the development of national vocal music education, we must first change the traditional way of thinking and establish a diversified education concept so that the music culture among all ethnic groups can achieve better communication and development. In the process of developing professional national vocal music education, in addition to the need to inherit the excellent traditional music culture of our nation, we must also absorb the essence of other cultures and promote the educational reform of national vocal music in a multidimensional perspective. First, conduct a thorough and thorough study of traditional national vocal singing theory. China has a history of 5,000 years of civilization, and traditional culture has also infiltrated the blood and bone marrow of Chinese people. In the teaching process, it is necessary to strengthen the study of national vocal music related theories, seek the connection between modern national vocal music and traditional national vocal music, inherit the essence of traditional national vocal music culture, and combine theoretical research with practical teaching activities to form a unique Second, the multidimensional vision, that is, the need to respect the equal development of multiple cultures, in the process of development so that all ethnic cultures can respect each other and develop on an equal footing [3].

The development of professional national vocal music education in China also requires the scientific and rational setting of teaching courses, and the timely adjustment of irrational teaching methods, teaching models and curriculum settings in the current national vocal music education. National vocal music education curriculum must follow the principle of combining nationalism and pluralism. Not only does it need to inherit excellent traditional culture, but also it requires continuous innovation, so that the curriculum is more practical and comprehensive, so that students can be better trained. The unique singing style and singing ability enable students to achieve the perfect combination of sound, emotion and performance.

Nowadays professional vocal music teaching in China's universities and colleges mostly uses one-on-one teaching models. Although this teaching model is flexible and targeted, it also has certain deficiencies, making the students' performance forms too single. The limited horizons affect the overall ability of students. Therefore, we must change the teaching methods, such as "open class", "group class", "non-governmental interactive courses", so that students form a benign interaction and competition in learning, and further broaden their horizons and improve their overall artistic skills [4].

The professional level of teachers is very important to the national vocal music education. Therefore, teachers' teaching ideas and teaching ideas must be further updated. Teachers should improve their comprehensive cultural qualities, teaching abilities, and professional qualities. That is to say, the teachers' background in the current multidimensional cultural development. Next, it is necessary to skillfully apply various teaching techniques in the teaching of national vocal music, to acquire rich theoretical knowledge, to have diversified teaching concepts and scientific teaching methods; to carry out various scientific research activities in teaching activities, teachers must have Excellent professional knowledge and professional qualities can accurately understand the connotation of vocal music works and thus guide students correctly. The singing and teaching of vocal music have commonness and individuality. Music is time, auditory performance, fluid art, and emotional art. In the process of expression, commonness is in individuality, universality exists in particularity, in national vocal music, Shanxi The strong folk songs are the foundation of our characteristic vocal music education model. On this basis, in the vocal music teaching, it is necessary to aggravate the target amount of Shanxi folk songs in order to meet the qualitative requirements. Singing method of singing, the style of the style, the two can not be confused with one another, can not replace each other. Singing is the method of singing, which is the means and tools of artistic expression, such as the unity of the vocal area, the fact that the characters are open, the opening of the throat, the resonance of the mask, and other singing principles. Technology serves art performance and it is in a subordinate position. The style is the style of artistic expression and style, which belongs to the category of artistic personality. Style-to-singing is prescriptive and selective, and singing is adaptable to style and dependent on style. What kind of sound techniques 
are used to express the style of vocal music is a subtle aspect that needs special attention as vocal music. Studying singing style from the perspective of style can not only enrich the technique but also discover the scientific mysteries that are highly consistent with singing style. If Pavarotti sings Napoli's folk songs and opera arias, the different techniques and performances give people different aesthetics. The singers Song Zuying and Yan Weiwen are equally so. The folk songs of Shanxi include Niu Baolin, Shan Jun, Ma Xiao, Fan Xiudong, Liu Gaixiu, and Guo Huxi. This is the same work performed by different people in the same department. The style and technique are also subtly different. The aesthetic effects are very different. Superb craftsmanship, distinctive style, and unpretentious performance mentality are necessary for every singer. Touching people and entertaining talents are the highest goals pursued [5].

\section{Conclusion}

Due to the influence of Western music culture, there are still many problems in the professional national vocal music education model adopted by the major music academies in China, which makes the students' singing styles too simple. However, we are now living in a culturally diverse society. The development of professional national vocal music education needs to meet the requirements of the times, change the traditional teaching philosophy, set up the curriculum scientifically and reasonably, improve the overall quality of teachers, and innovate teaching methods, etc., and promote professional national vocal music education. Long-term development.

\section{References}

[1] Wang Ying. Integration and Practice - Discussion on Multicultural Music Education the National Vocal Music Teaching in Higher Music Colleges Under the Scenery[J]. Xi'an Musicology Journal of Chinese Academy of Sciences, 2012, (2):122-126.

[2] Ling Huqing. The Absorption of Multiculturalism in College National Vocal Music Education Its own evolution [J]. Heilongjiang Higher Education Research, 2013, (11): 106-108.

[3] Wang Zhimin. A Brief Analysis of Chinese Vocal Music Education in the Perspective of Multiculturalism[J]. Journal of Heilongjiang Institute of Education, 2014, (5):13-15.

[4] Wen Meiqin. National Cultural Education in Vocal Music Teaching in Normal University under the View of Culture the Necessity of Raising [J]. Music Time, 2014, (14): 138-139.

[5] Li Yudan. Higher National Vocal Music Teaching in the Perspective of New Age Culture the Diversification of Learning [J]. Art Research, 2015, (1): 144-147. 